\title{
Distribuição radicular do maracujazeiro sob diferentes doses de potássio aplicadas por fertirrigação
}

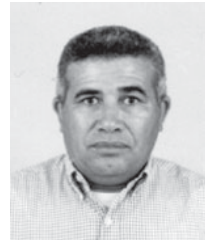

\author{
Valdemício F. de Sousa ${ }^{1}$, Marcos V. Folegatti ${ }^{2}$, Maurício A. Coelho Filho ${ }^{3}$ \& José A. Frizzone ${ }^{4}$ \\ 1 Embrapa Meio-Norte, Av. Duque de Caxias 5650, Bairro Buenos Aires, CP 01, CEP 64006-220, Teresina, PI. \\ Fone: (86) 2251141 E-mail: vfsousa@cpamn.embrapa.br (Foto) \\ 2 ESALQ/USP. CP 9, CEP 13418-900, Piracicaba, SP. Fone: (19) 3429-4217. E-mail: mvfolega@carpa.ciagri.usp.br \\ 3 ESALQ/USP. E-mail: macoelho@carpa.ciagri.usp.br \\ 4 ESALQ/USP. E-mail: frizzone@carpa.ciagri.usp.br
}

Protocolo $148-26 / 10 / 2001$

\begin{abstract}
Resumo: Objetivou-se, com este trabalho, estudar o efeito de cinco doses de potássio aplicadas através da água de irrigação por gotejamento sobre o comprimento, a área e a distribuição espacial do sistema radicular do maracujazeiro amarelo (Passiflora edulis Sims. f. flavicarpa Deg) utilizando-se a técnica auxiliada por imagens digitalizadas. O experimento foi realizado no Campo Experimental da ESALQ/USP, em Piracicaba, São Paulo, na latitude de $22^{\circ} 42^{\prime} 30^{\prime \prime S}$ e longitude de $47^{\circ} 38^{\prime} 00^{\prime \prime} \mathrm{W}$. Foram testadas cinco doses de potássio: 0; 0,225; 0,450; 0,675 e 0,900 kg planta-1 ano $^{-1}$ de $\mathrm{K}_{2} \mathrm{O}$, aplicadas via água de irrigação por gotejamento a cada sete dias. A avaliação do comprimento e da área de raízes foi feita utilizando-se o software SIARCS e os resultados analisados em gráficos Box-plot, gráficos com colunas e de isolinhas de contorno. O comprimento e a área radicular do maracujazeiro reduziram-se com a profundidade do perfil e os maiores valores se concentraram na camada de $0-0,40 \mathrm{~m}$. As doses de potássio, 0 e 0,675 kg planta ${ }^{-1} \mathrm{ano}^{-1}$ de $\mathrm{K}_{2} \mathrm{O}$ favoreceram maiores valores de comprimento e de área radicular do maracujazeiro amarelo.
\end{abstract}

Palavras-chave: maracujazeiro, área de raiz, manejo de nutrientes, gotejamento

\section{Root distribution of the passion fruit under different doses of potassium applied through fertigation}

\begin{abstract}
The objective of this work was to study the effect of different doses of potassium applied through fertigation by drip irrigation system on the length, area and spatial distribution of the root system of the yellow passion fruit plant (Passiflora edulis Sims. f. flavicarpa Deg), using digital image technique. The experiment was conducted at the Experimental Area of ESALO/ USP, Piracicaba, São Paulo State, Brazil, Latitude $22^{\circ} 42^{\prime} 30^{\prime \prime} S$ and Longitude $47^{\circ} 38^{\prime} 00^{\prime \prime} W$. Five potassium doses $0,0.225,0.450,0.675$ and $0.900 \mathrm{~kg} \mathrm{plant}^{-1}$ year ${ }^{-1}$ of $_{\mathrm{K}_{2}} \mathrm{O}$ were tested. The potassium doses were applied through irrigation water with seven-days frequency. The SIARCS software was used for the root system evaluation. The root length and area of passion fruit plant reduced with the soil profile depth, and the largest concentrations values were registered up to $0.40 \mathrm{~m}$ of depth. The potassium doses of $\mathrm{O}$ and $0.675 \mathrm{~kg} \mathrm{plant}^{-1}$ year $^{-1}$ of $\mathrm{K}_{2} \mathrm{O}$ favored higher values of root length and area of the yellow passion fruit plant.
\end{abstract}

Key words: passion fruit, root area, nutrient management, drip irrigation

\section{INTRODUÇÃO}

O maracujazeiro amarelo (Passiflora edulis Sims f. flavicarpa Deg) é uma frutífera bastante cultivada no Brasil e de bom retorno econômico para os produtores. Com área plantada de 33.012 ha, o Brasil aparece como o principal produtor mundial de maracujá destacando-se, como maiores produtores, os estados da Bahia, Sergipe, São Paulo, Pará, Minas Gerais, Ceará, Alagoas e Rio de Janeiro. Na Região Sudeste, a área cultivada com o maracujazeiro tem aumentado expressivamente nos últimos anos, tornando-a uma das dez espécies frutíferas mais cultivadas (FNP Consultoria \& Comércio, 2001).

Apesar dessa expansão, a produtividade nacional é muito variada e, na maioria das vezes, baixa, em relação ao potencial produtivo da cultura. Por isso, a literatura mostra que há necessidade de tecnologias de manejo de água e nutrientes para a cultura, capazes de proporcionar o aumento da produtividade e da qualidade dos frutos para melhor competir nos mercados nacional e internacional (Ruggiero et al., 1996).

A utilização adequada da água em cultivos irrigados tem condicionado aos produtores a garantia da produção; todavia, 
a maximização dos recursos naturais e o aumento da produtividade, não se dão apenas com o fornecimento de água às culturas. A elevação dos níveis de fertilidade do meio é também muito importante para o desenvolvimento e produção das plantas. Nos últimos anos, a forma tradicional de aplicação de fertilizantes nas culturas irrigadas vem sendo substituída pela fertirrigação, que permite a aplicação de fertilizantes simultaneamente com a água de irrigação. Neste caso, por sua forma de aplicação de água, a irrigação por gotejamento tem-se mostrado bastante eficiente no cultivo de fruteiras, uma vez que a água e os fertilizantes são aplicados pontualmente na zona de concentração das raízes, o que aumenta a eficiência de uso dos mesmos (Phene et al., 1979).

No manejo de água e nutriente, o conhecimento da distribuição do sistema radicular das culturas é indispensável. A densidade e a profundidade das raízes permitem não somente a determinação da lâmina necessária de irrigação mas, também, a distribuição dos fertilizantes em locais adequados, de forma a reduzir as perdas e aumentar a eficiência de uso pelas plantas. Poucos foram os trabalhos realizados para se estudar o sistema radicular do maracujazeiro, que é do tipo pivotante, pouco profundo e concentrado próximo ao caule, com maior volume de raízes, 60 a $80 \%$, concentrados entre 0,30 e $0,45 \mathrm{~m}$ de profundidade e em raio de $0,60 \mathrm{~m}$ a partir do caule (Medina et al., 1980; Urashima,1985; Kliemann et al., 1986).

Em um estudo desenvolvido na África do Sul com o maracujazeiro irrigado por pequenas bacias em torno das plantas, Kuhne (1965) observou que $81,6 \%$ das raízes se concentravam entre 0,15 e 0,45 m de distância em relação ao caule e $87 \%$ se situaram em torno de $0,45 \mathrm{~m}$ de profundidade. Carvalho (1988) avaliando a distribuição do sistema radicular do maracujazeiro amarelo verificou que as raízes se concentraram num raio de $0,50 \mathrm{~m}$ até uma profundidade $0,40 \mathrm{~m}$, com maior quantidade até $0,20 \mathrm{~m}$ de raio e de profundidade.

O sistema radicular do maracujazeiro possui desenvolvimento rápido, entre 210 e $300 \mathrm{~d}$, estabilizando-se em seguida (Haag et al., 1973). Este comportamento pode ser afetado pelo tipo de solo e sistema de manejo, principalmente água e nutrientes, destacando-se a localização dos fertilizantes (Borges, 1995). De acordo com Countanceau (1971) em plantas desenvolvidas em solos com fertilidade média, as raízes tendem a se estender mais que em solos férteis, sendo maior na superfície que em profundidade. Portanto, plantas cultivadas com diferentes doses de potássio, podem ter comportamento distinto de desenvolvimento de raízes, principalmente quando esses são aplicados via água de irrigação localizada, pois a solução fertilizante pode provocar alterações freqüentes na condutividade elétrica da solução do solo, afetando o desenvolvimento das raízes.

De maneira geral, os estudos de raízes têm-se limitado às determinações de matéria seca, como mostraram Menzel et al. (1986), Menzel \& Simpson (1988) e Menzel et al. (1991) para o maracujazeiro. Poucos são os trabalhos cuja finalidade tem sido estudar, também, comprimento e/ou área superficial de raízes, para avaliar a área potencial destinada à absorção da solução do solo.

Vários são os métodos para se avaliar a distribuição do sistema radicular no perfil do solo. Com o avanço da informática, novas metodologias foram propostas, apresentando menores custos, maior precisão e menor tempo de análises, dentre as quais se destaca o método de imagens digitalizadas desenvolvido por Crestana et al. (1994) utilizado com sucesso por Santos (1997), Fante Júnior et al. (1999) e Machado \& Coelho (2000) na avaliação de raízes de mangueira, aveia e lima ácida tahiti, respectivamente.

Objetivou-se, com este trabalho, estudar o efeito de cinco doses de potássio aplicadas através da água de irrigação por gotejamento sobre o comprimento, a área e a distribuição espacial do sistema radicular do maracujazeiro amarelo, utilizando-se a técnica auxiliada por imagens digitalizadas.

\section{MATERIAL E MÉTODOS}

O experimento foi realizado no Campo Experimental da Fazenda Areão, pertencente à ESALQ/USP, localizado no município de Piracicaba, São Paulo, na latitude de 2242’30”S, longitude $47^{\circ} 38^{\prime} 00^{\prime \prime}$ W e altitude $576 \mathrm{~m}$.

Para a caracterização física e química do solo foram retiradas amostras nas camadas de 0 - 0,20 m, 0,20 - 0,40 m e 0,40 - 0,60 m (Tabelas 1 e 2).

Tabela 1. Caracterização química do solo da área experimental: pH, matéria orgânica (M.O), macronutrientes, capacidade de troca de cátions $(\mathrm{T})$ e saturação por bases $(\mathrm{V})$

\begin{tabular}{|c|c|c|c|c|c|c|c|c|c|}
\hline $\begin{array}{c}\text { Camada } \\
\mathrm{m}\end{array}$ & $\begin{array}{c}\mathrm{pH} \\
\mathrm{CaCl}_{2}\end{array}$ & $\begin{array}{l}\text { M.O } \\
\text { g dm }^{-3}\end{array}$ & $\begin{array}{c}\mathrm{P} \\
\mathrm{mg} \mathrm{dm}\end{array}$ & K & \multicolumn{3}{|c|}{$\mathrm{nmol}_{\mathrm{c}} \mathrm{dm}^{-3}$} & $\mathrm{~T}$ & $\%$ \\
\hline 0 & 5,20 & 14 & 4 & 1,50 & 33 & 13 & 28 & 75,50 & 63 \\
\hline & 5,00 & 17 & 4 & 1,60 & 28 & 12 & 31 & 72,60 & 57 \\
\hline $0,40-0,60$ & 5,30 & 9 & 6 & 0,50 & 32 & 6 & 22 & 60,50 & 64 \\
\hline
\end{tabular}

Tabela 2. Caracterização física do solo da área experimental: capacidade de campo (CC), ponto de murcha permanente (PMP), densidade global (dg) e teores de argila, silte e areia

\begin{tabular}{|c|c|c|c|c|c|c|}
\hline \multirow{2}{*}{$\begin{array}{c}\text { Camada } \\
\mathrm{m}\end{array}$} & $\mathrm{CC}$ & PMP & \multirow{2}{*}{$\underset{\mathrm{kg} \mathrm{dm}}{\mathrm{dg}}$} & Argila & Silte & Arei \\
\hline & \multicolumn{2}{|c|}{$\mathrm{cm}^{3} \mathrm{~cm}^{-3}$} & & & $\mathrm{~g} \mathrm{~kg}^{-1}$ & \\
\hline $0-$ & 0,4148 & 0,3472 & 1,49 & 624,0 & 172,0 & 204 \\
\hline $0,20-$ & 0,4193 & 0,3491 & 1,46 & 694,3 & 138,3 & 167,4 \\
\hline $0,40-0,60$ & 0,4500 & 0,3808 & 1,43 & 688,9 & 136,4 & 174,8 \\
\hline
\end{tabular}

O preparo do solo se consistiu de duas gradagens com posterior aplicação e incorporação de 2,0 t ha ${ }^{-1}$ de calcário dolomítico $60 \mathrm{~d}$ antes do transplantio das mudas, para elevação da saturação por bases a $80 \%$.

As covas foram abertas no espaçamento de 3,5 x 4,0 m, de formato cilíndrico, com 1,0 $\mathrm{m}$ de diâmetro e $0,5 \mathrm{~m}$ de profundidade e a adubação de fundação foi feita por cova com $40 \mathrm{~L}$ de esterco de curral, 0,20 $\mathrm{kg} \mathrm{P}_{2} \mathrm{O}_{5}$ (superfosfato simples), $0,004 \mathrm{~kg}$ de $\mathrm{Zn}$ (sulfato de zinco) e 0,001 kg de B (ácido bórico).

O sistema de irrigação foi o gotejamento, com gotejadores de vazão 2,4 $\mathrm{L} \mathrm{h}^{-1}$. Os gotejadores, em número de cinco, foram dispostos em círculo, com raio médio de $0,40 \mathrm{~m}$ do caule da planta. A quantidade de água aplicada foi definida de acordo com o balanço médio de entrada e saída de água em lisímetros de drenagem instalados no centro da área experimental. $\mathrm{O}$ monitoramento da umidade no solo foi feito com tensiômetros instalados a $0,30 \mathrm{~m}$ do caule da planta e as profundidades de $0,10,0,30,0,50$ e $0,70 \mathrm{~m}$. 
As adubações de formação e de produção, com nitrogênio e potássio, foram feitas através da água de irrigação, na freqüência de aplicação de $7 \mathrm{~d}$. A adubação nitrogenada foi feita à base de 0,10 e $0,38 \mathrm{~kg}_{\text {planta- }}{ }^{-1}$ de $\mathrm{N}$ nas fases de formação e de produção, respectivamente. As doses de potássio foram definidas para as duas fases, segundo os tratamentos estabelecidos (Tabela 3), sendo que na primeira fase utilizou-se cloreto de potássio e, na segunda, nitrato de potássio.

Tabela 3. Doses de potássio aplicadas por tratamento nas fases de formação das plantas e de produção

\begin{tabular}{cccc}
\hline \multirow{2}{*}{ Tratamentos } & \multicolumn{3}{c}{ Doses de Potássio $\left(\mathrm{kg} \mathrm{de} \mathrm{K}_{2} \mathrm{O} \mathrm{planta}^{-1}\right.$ ano $\left.^{-1}\right)$} \\
\cline { 2 - 4 } & $\begin{array}{c}\text { Fase de } \\
\text { Formação }\end{array}$ & $\begin{array}{c}\text { Fase de } \\
\text { Produção }\end{array}$ & Total \\
\hline $\mathrm{K}_{0}$ & 0 & 0 & 0 \\
$\mathrm{~K}_{1}$ & 0,25 & 0,200 & 0,225 \\
$\mathrm{~K}_{2}$ & 0,50 & 0,400 & 0,450 \\
$\mathrm{~K}_{3}$ & 0,75 & 0,600 & 0,675 \\
$\mathrm{~K}_{4}$ & 0,100 & 0,800 & 0,900 \\
\hline
\end{tabular}

$\mathrm{Na}$ fase de formação, a distribuição dos nutrientes ao longo do ciclo da cultura foi feita de forma linear, em 15 aplicações. Durante a fase de produção, a aplicação dos nutrientes foi feita em 32 parcelas, segundo a curva de absorção de nutrientes para o maracujazeiro (Haag et al., 1973).

Para avaliação da distribuição das raízes, trincheiras foram abertas nas dimensões de $1,0 \mathrm{~m}$ de profundidade, $0,90 \mathrm{~m}$ do caule da planta na direção da linha de plantio, considerando-se os dois lados e 1,5 m do caule da planta na direção da entrelinha, a partir de $0,30 \mathrm{~m}$ do caule da planta. As avaliações foram feitas no mês de março, quando já haviam sido colhidos em torno de $70 \%$ dos frutos.

Após a abertura das trincheiras procedeu-se à limpeza e preparo das raízes, para posterior realização das imagens, adotando-se a seqüência: (i) exposição das raízes através de lavagem com água sob pressão, com auxílio de um pulverizador costal; (ii) pintura localizada das raízes com tinta spray de coloração branca, para aumentar o contraste em relação ao solo da parede da trincheira; (iii) demarcação do perfil do solo com um reticulado de $0,20 \times 0,20 \mathrm{~m}$, feito com madeira e barbante, nas dimensões de $1,80 \mathrm{~m}$ de comprimento e $1,0 \mathrm{~m}$ de altura; (iv) elaboração das imagens de cada quadrícula, para o qual utilizouse uma máquina fotográfica digital (imagem já digitalizada); (v) processamento das imagens através do "software" SIARCS (Sistema Integrado para Análise de Raízes e Cobertura do Solo) desenvolvido pela EMBRAPA/CNPDIA (Crestana et al., 1994) que permite avaliar a distribuição do sistema radicular da cultura por meio das imagens digitalizadas.

Os resultados de comprimento e área de raízes foram analisados através de gráficos Box-plot, gráficos com colunas e de isolinhas de contorno.

\section{RESULTADOS E DISCUSSÃO}

A avaliação da distribuição do sistema radicular do maracujazeiro ocorreu através da distribuição espacial da área $\left(\mathrm{cm}^{2}\right.$ de raiz por $400 \mathrm{~cm}^{2}$ de solo) e do comprimento ( $\mathrm{cm}$ de raiz por $400 \mathrm{~cm}^{2}$ de solo) de raízes, da distribuição percentual do comprimento e área radicular (na profundidade e na horizontal) e da distribuição acumulada de raízes. Os resultados obtidos nas imagens digitais foram apresentados em gráficos de contorno, em que o caule da planta está localizado sempre na coordenada $(0,0)$ no centro.

Pela distribuição da área de raízes (Figura 1) verificaram-se variações de até $33 \mathrm{~cm}^{2}$ de raiz por $400 \mathrm{~cm}^{2}$ de solo, sendo que os maiores valores de área radicular foram registrados com a dose de potássio $\mathrm{K}_{3}$, com distribuição variando de 3 a $33 \mathrm{~cm}^{2}$ de raiz por $400 \mathrm{~cm}^{2}$ de solo em todo o perfil estudado. As menores concentrações foram obtidas nas plantas fertirrigadas, com as doses $\mathrm{K}_{4}$ e $\mathrm{K}_{2}$, cujos valores foram menores que $12 \mathrm{~cm}^{2}$ de raiz por $400 \mathrm{~cm}^{2}$ de solo, distribuídos em torno de $0,40 \mathrm{~m}$ de profundidade. Com as doses de potássio $\mathrm{K}_{0} \mathrm{e} \mathrm{K}_{1}$, a distribuição de raízes foi detectada em todo o perfil; no entanto, os valores registrados de área radicular para $\mathrm{K}_{0}$ variaram em torno de $24 \mathrm{~cm}^{2}$ de raiz por $400 \mathrm{~cm}^{2}$ de solo, enquanto para $\mathrm{K}_{1}$, os valores chegaram a cerca de $15 \mathrm{~cm}^{2}$ de raiz por $400 \mathrm{~cm}^{2}$ de solo.

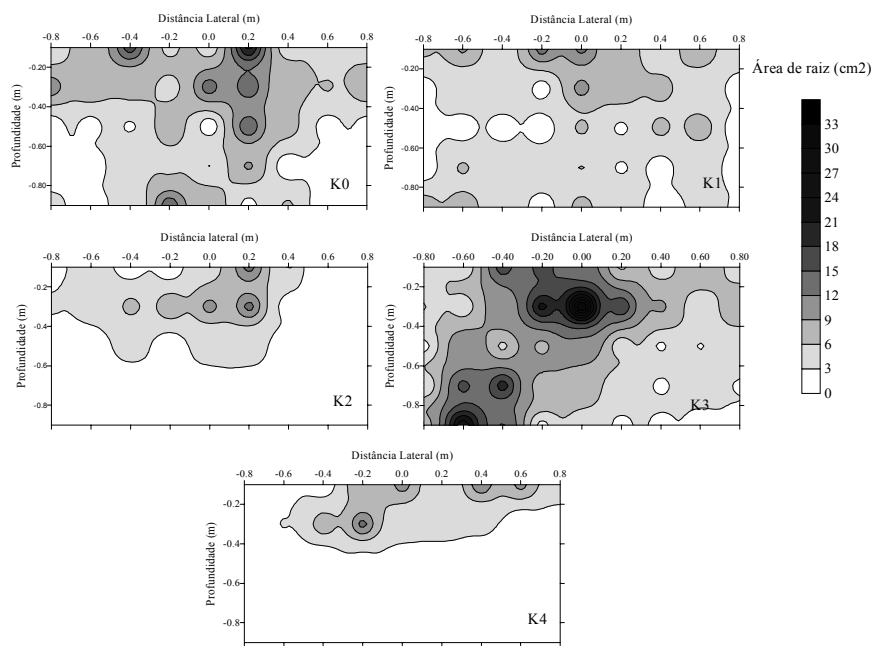

Figura 1. Distribuição espacial da área de raízes $\left(\mathrm{cm}^{2}\right.$ de raiz por $400 \mathrm{~cm}^{2}$ de solo) do maracujazeiro amarelo sob as doses de potássio $\mathrm{K}_{0}, \mathrm{~K}_{1}, \mathrm{~K}_{2}, \mathrm{~K}_{3}$ e $\mathrm{K}_{4}$, aplicadas por gotejamento

A distribuição espacial do comprimento de raízes por plantas (cm de raiz por $400 \mathrm{~cm}^{2}$ de solo) mostrou comportamento semelhante ao verificado para a área, porém com valores maiores (Figura 2). Da mesma forma que na área, o comprimento de
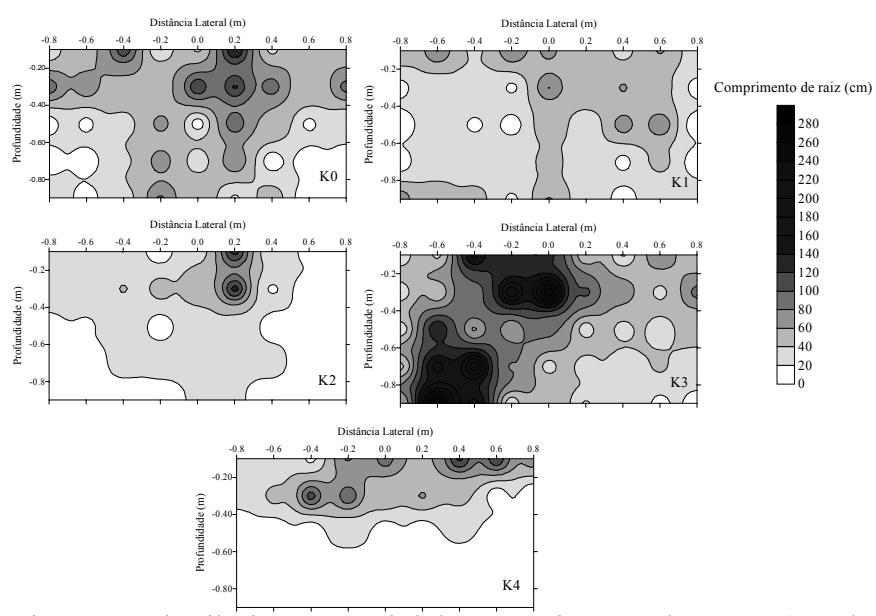

Figura 2. Distribuição espacial do comprimento de raízes ( $\mathrm{cm}$ de raiz por $400 \mathrm{~cm}^{2}$ de solo) do maracujazeiro amarelo sob as doses de potássio $\mathrm{K}_{0}, \mathrm{~K}_{1}, \mathrm{~K}_{2}, \mathrm{~K}_{3}$ e $\mathrm{K}_{4}$, aplicadas por gotejamento 
raízes verificado nas plantas que receberam a dose de potássio $\mathrm{K}_{3}$, foi registrado em todo o perfil, com maiores concentrações (60 a $280 \mathrm{~cm}$ de raiz por $400 \mathrm{~cm}^{2}$ de solo) desde próximo à superfície até praticamente $1,0 \mathrm{~m}$ de profundidade, tendendo para o lado esquerdo da planta, fato que pode estar relacionado com a posição dos gotejadores em volta da planta.

As plantas que receberam as doses de potássio $\mathrm{K}_{0}, \mathrm{~K}_{1}$ e $\mathrm{K}_{3}$ apresentaram distribuição de raízes em todo o perfil; já as que foram tratadas com $\mathrm{K}_{2}$ e $\mathrm{K}_{4}$ o comportamento foi diferenciado, principalmente para a dose $\mathrm{K}_{4}$, onde foram constatadas pequenas concentrações e poucas raízes finas. Isto pode estar relacionado com a quantidade de potássio aplicada $(0,900 \mathrm{~kg}$ planta $^{-1}$ de $\mathrm{K}_{2} \mathrm{O}$ ) e ter favorecido a elevação da condutividade elétrica no perfil do solo, afetando o desenvolvimento das raízes. Sousa (1993) verificou, no meloeiro que a aplicação de elevada quantidade de potássio via fertirrigação proporcionou a formação de raízes mais grossas, com distribuição não uniforme no perfil do solo. Este problema pode ter ocorrido em razão do maracujazeiro ser muito sensível à salinidade, cujos valores de condutividade elétrica do extrato de saturação do solo não devem ser maiores que $1,3 \mathrm{dS} \mathrm{m}^{-1}$ sem perda expressiva do seu rendimento potencial (Ayers \& Westcot, 1991).

Os resultados obtidos ao longo da profundidade mostraram que as distribuições percentuais do comprimento de raízes (Figura 3A) e da área de raízes (Figura 3B) tiveram comportamento semelhante, independente da dose de potássio fornecida,
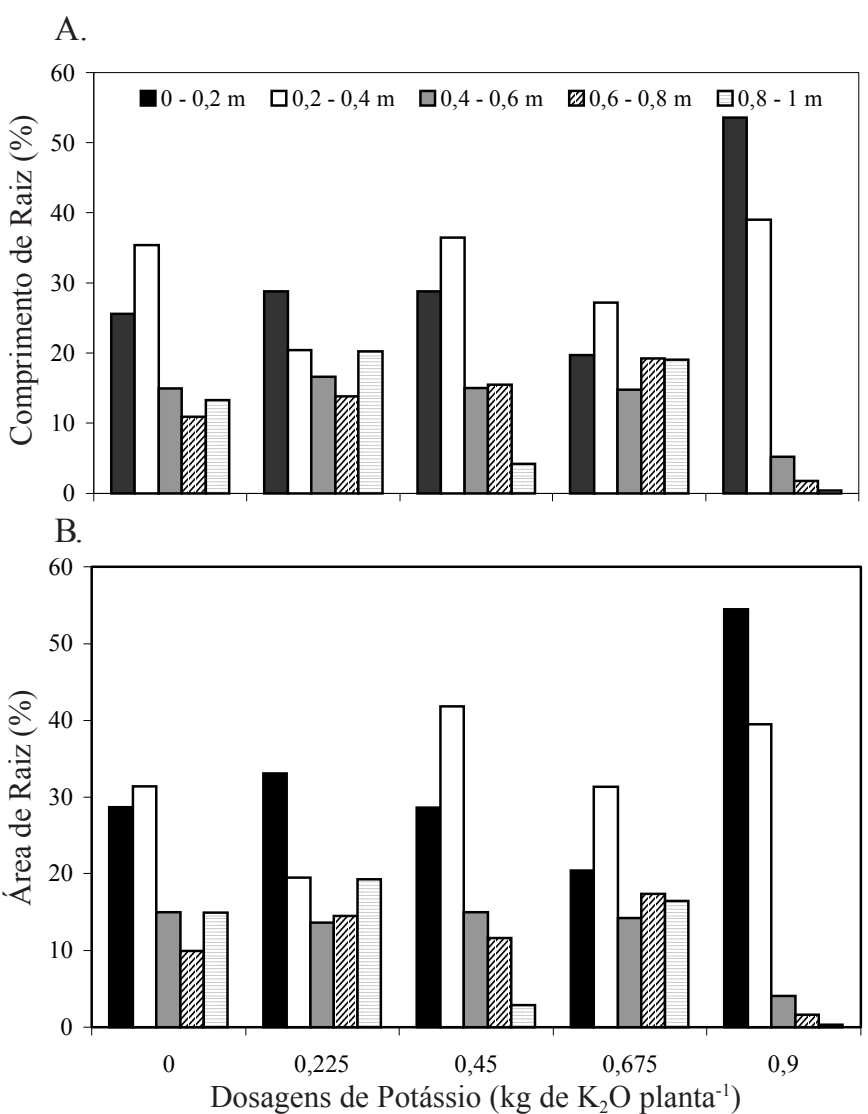

Figura 3. Efeito de doses de potássio sobre a distribuição percentual do comprimento (A) e da área de raízes (B) do maracujazeiro amarelo, em função da profundidade

e as maiores concentrações de raízes localizaram-se numa faixa de 0 a $0,40 \mathrm{~m}$ de profundidade. Essa distribuição está em acordo com os resultados obtidos por Carvalho (1988) e com as assertivas de Manica (1981); Urashima (1985) e Kliemann et al. (1986) sobre distribuição de raízes do maracujazeiro, mencionando que a maior concentração das suas raízes se encontra entre 0,30 e $0,45 \mathrm{~m}$ de profundidade; contudo, verificaram-se diferenças expressivas entre a máxima $\left(0,900 \mathrm{~kg} \mathrm{planta}^{-1} \mathrm{de}_{2} \mathrm{O}\right)$ e as demais doses de potássio.

Ainda de acordo com a Figura 3, com a aplicação da dose de potássio $K_{4}, 92,69$ e 93,80\%, do comprimento e a área das raízes se concentraram, respectivamente, na camada de $0-0,40 \mathrm{~m}$, sendo que, desses, 53,63 e $54,30 \%$ foram confinados na camada superficial de 0 a $0,20 \mathrm{~m}$ do perfil do solo.

No tratamento que não recebeu potássio $\left(\mathrm{K}_{0}\right)$, cerca de $60,62 \%$ do comprimento e da área total das raízes foram distribuídas até $0,40 \mathrm{~m}$ de profundidade, sendo que se verificou, nas camadas seguintes, maior homogeneidade na distribuição radicular. A aplicação das doses $\mathrm{K}_{1}\left(0,225 \mathrm{~kg}_{\text {planta }}{ }^{-1}\right.$ de $\left.\mathrm{K}_{2} \mathrm{O}\right) \mathrm{e}$ $\mathrm{K}_{3}\left(0,675 \mathrm{~kg}_{\text {planta }}{ }^{-1}\right.$ de $\left.\mathrm{K}_{2} \mathrm{O}\right)$ resultou na distribuição radicular mais uniforme no perfil do solo.

A distribuição acumulada do comprimento e da área de raízes (Figura 4), confirma a abordagem feita sobre a Figura 3. Tanto para o comprimento como para a área de raízes, observou-se que, com a aplicação da dose de potássio $0,900 \mathrm{~kg} \mathrm{planta}^{-1}$ de $_{2} \mathrm{O}$, cerca de $90 \%$ das raízes do maracujazeiro se concentraram no perfil do solo, até os primeiros $0,40 \mathrm{~m}$ de profundidade. Com referência a $\mathrm{K}_{2}\left(0,450 \mathrm{~kg}_{\text {planta }}{ }^{-1}\right.$ de $\left.\mathrm{K}_{2} \mathrm{O}\right)$ basicamente a mesma concentração acumulada foi constatada à profundidade de $0,70 \mathrm{~m}$, enquanto para as demais doses de potássio, $90 \%$ de concentração das raízes foram registrados entre 0 e $0,90 \mathrm{~m}$.

Os resultados referentes à distribuição percentual do comprimento e da área de raízes em função da distância lateral

A. Comp. de Raiz Acum. (\%) $\begin{array}{lllll}20 & 40 & 60 & 80 & 100\end{array}$

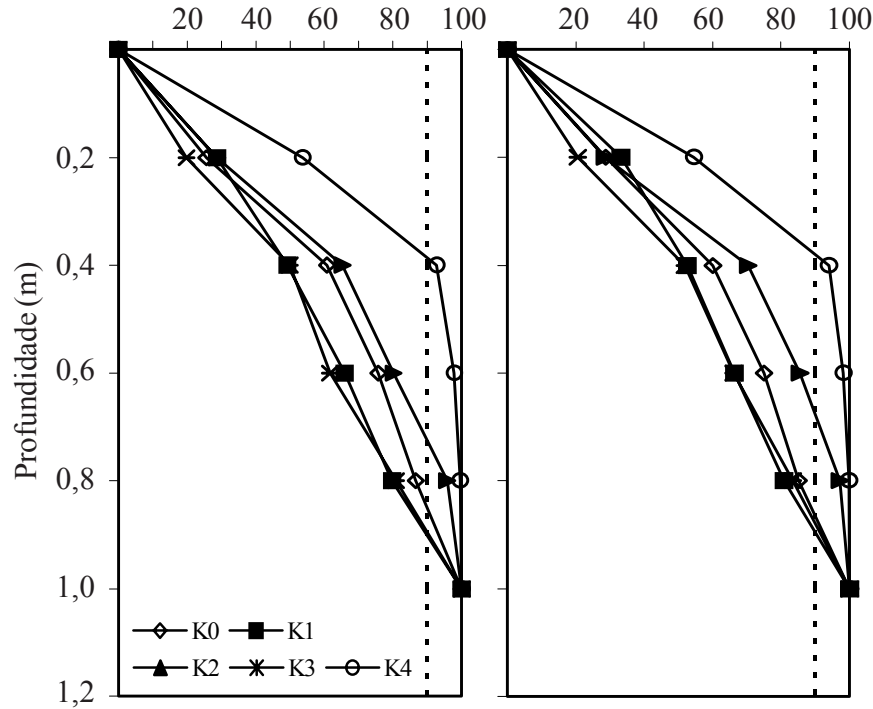

Figura 4. Efeito de doses de potássio na distribuição acumulada do comprimento (A) e da área de raízes (B) do maracujazeiro amarelo, em função da profundidade 
(Figura 5) indicam que a aplicação das doses de potássio $\mathrm{K}_{1}, \mathrm{~K}_{3}$ e $\mathrm{K}_{4}$, resulta na distribuição percentual radicular mais uniforme em relação ao caule da planta. As plantas com ausência de potássio $\left(\mathrm{K}_{0}\right)$ e com a aplicação de $0,450 \mathrm{~kg}_{\text {planta }}{ }^{-1}$ de $\mathrm{K}_{2} \mathrm{O}\left(\mathrm{K}_{2}\right)$ apresentaram as maiores concentrações de comprimento e de área radicular, nas distâncias de 0,10 e 0,30 m do caule, com valores que variaram de 35,63 a $41,12 \%$ e de 39,65 a $39,05 \%$, respectivamente. Este comportamento dos dados diverge da distribuição radicular observada para as demais doses de potássio, cujas distribuições de raízes em relação ao caule, foram mais constantes, com concentrações abaixo das verificadas para $\mathrm{K}_{0}$ e $\mathrm{K}_{2}$ nas duas primeiras camadas, comportamento este que diverge de Carvalho (1988) ao observar que 70,17\% das raízes do maracujazeiro se concentram na faixa de $0,20 \mathrm{~m}$ do caule da planta; todavia, aproxima-se de Manica (1981); Urashima (1985) e Kliemann et al. (1986) que ao discorrerem sobre distribuição de raízes do maracujazeiro, informam que o maior volume de raízes, 60 a $80 \%$, se concentra num raio de $0,60 \mathrm{~m}$, a partir do caule, fato que pode estar relacionado às condições físicas e químicas do solo e ao manejo da cultura, principalmente de irrigação, uma vez que esses fatores interferem no desenvolvimento e na distribuição do sistema radicular das plantas.

A distribuição acumulada de comprimento de raízes (Figura 6A) e de área de raízes (Figura 6B) com relação à distância lateral, apresentou comportamento semelhante, tanto entre as doses de potássio como entre distâncias do caule da planta. Para as duas situações, $90 \%$ das raízes se concentraram entre 0,70 e $0,80 \mathrm{~m}$ do caule da planta.
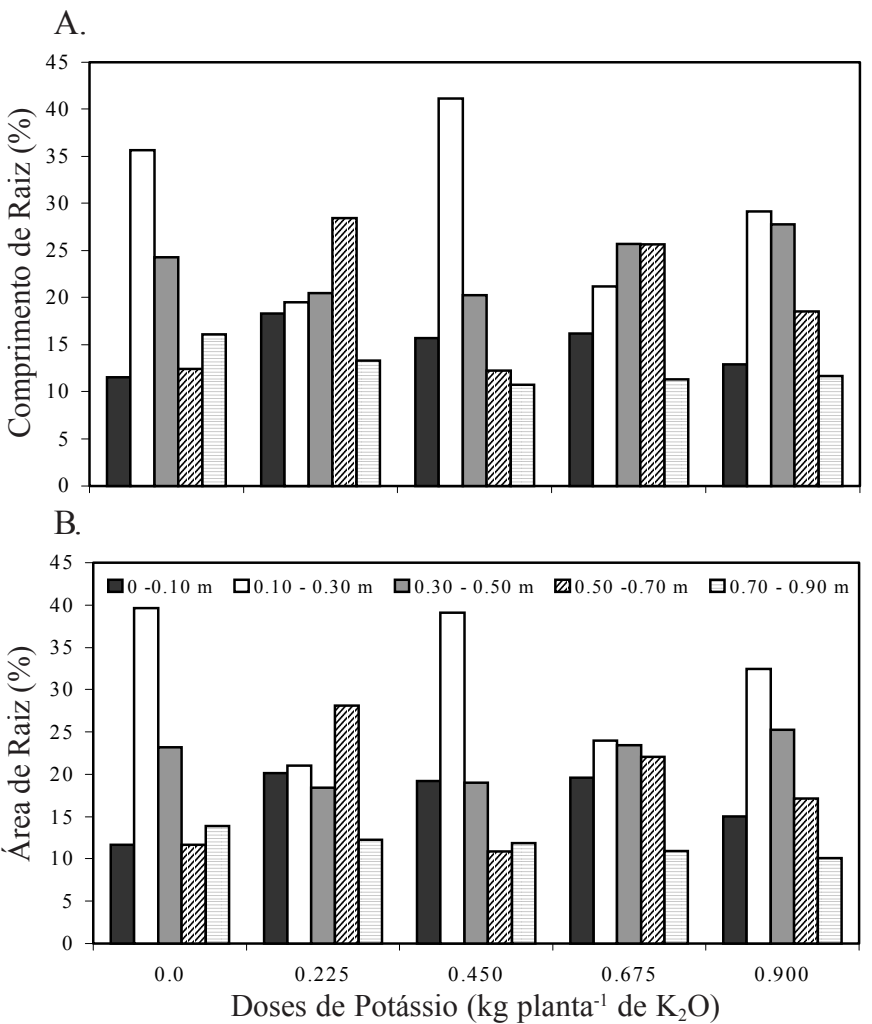

Figura 5. Efeito de doses de potássio na distribuição percentual de comprimento (A) e da área de raízes (B) do maracujazeiro amarelo, em função da distância lateral
A.

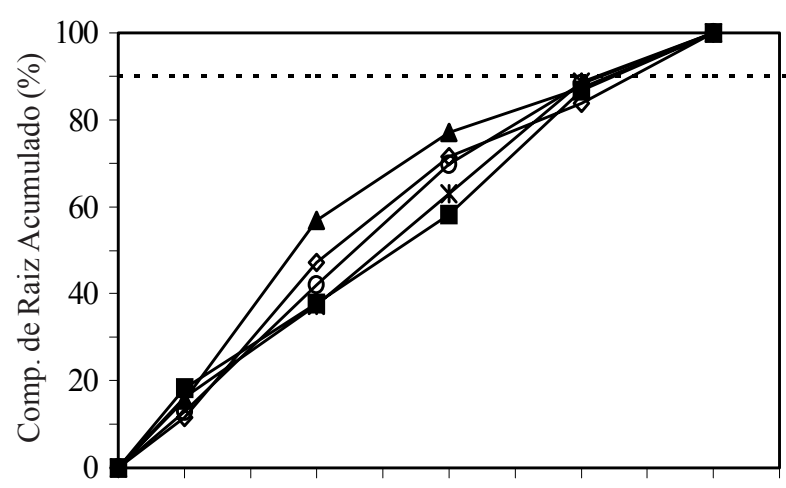

B.

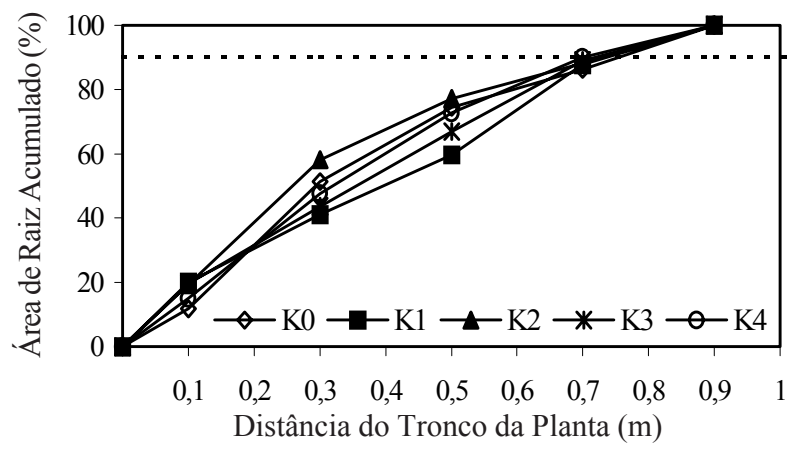

Figura 6. Efeito de doses de potássio no comprimento (A) e na área de raízes acumuladas (B) do maracujazeiro amarelo, em função da distância lateral

\section{CONCLUSÕES}

1. O comprimento e a área radicular do maracujazeiro reduziram-se com a profundidade do perfil e os maiores valores se concentraram na camada de $0-0,40 \mathrm{~m}$.

2. As doses de potássio, 0 e $0,675 \mathrm{Kg} \mathrm{K}_{2} \mathrm{O}$ planta $^{-1} \mathrm{ano}^{-1}\left(\mathrm{~K}_{0}\right.$ e $\mathrm{K}_{3}$ ) favoreceram maiores valores de comprimento e de área radicular do maracujazeiro amarelo.

\section{LITERATURA CITADA}

Ayers, R.S.; Westcot, D.W. A qualidade da água na agricultura. Campina Grande: UFPB, 1991.218p. Estudos da FAO Irrigação e Drenagem, 29 revisado

Borges, A.L. Nutrição e adubação do maracujazeiro. Cruz das Almas: Embrapa Mandioca e Fruticultura, 1995. 29p.

Carvalho, L.C. Estudo da distribuição do sistema radicular do maracujazeiro amarelo. In: Congresso Brasileiro de Fruticultura, 9, 1987, Campinas. Anais... Campinas: Sociedade Brasileira de Fruticultura, 1988. p.609-612.

Countanceau, M. Fruticultura, técnica y economía de los cultivos de rosáceas leñosa productores de frutas. Barcelona: OIKOS-TAU, 1971.608p.

Crestana, S.; Guimarães, M.F.; Jorge, L.A.C.; Ralisch, R.; Tozzi, C.L.; Torre Neto, A.; Vaz, C.M.P. Avaliação da distribuição de raízes no solo auxiliada por processamento de imagens digitais. Revista Brasileira de Ciência do Solo, Campinas, v.18, n.3, p.365-371, 1994.

Fante Jr., L.; Reichardt, K.; Jorge, L.A.C Distribuição do sistema radicular de uma cultura de aveia forrageira. Scientia Agricola, Piracicaba, v.56, n.4. spl., p.1091-1100, 1999. 
FNP Consultoria \& Comércio. Agrianual 2001: Anuário da Agricultura Brasileira. São Paulo, 2001, 545p.

Haag, H.P.; Oliveira, G.D.; Borduchi, A.S.; Sarruge, J.R. Absorção de nutrientes por duas variedades de maracujá. ESALQ/USP. Anais... Escola Superior de Agricultura "Luiz de Queiroz" Universidade de São Paulo, v.30, p.267-279, 1973.

Kliemann, H.J.; Campelo Júnior, J.H.; Azevedo, J.A.; Guilherme, M.R.; Genú, P.J.C. Nutrição mineral e adubação do maracujazeiro. In: Haag, H. P. Nutrição mineral e adubação de fruteiras tropicais. Campinas: Fundação Cargill, 1986. p.247-284.

Kuhne, F.A. Tasty granadillas and their root systems. Farming South Africa, Pretoria, v.41, n.2, p.33-37. 1965.

Machado, C.C.; Coelho, R.D. Estudos da distribuição espacial do sistema radicular do limão 'Crava' enxertado com lima ácida “Tahiti”. Laranja, Cordeiropolis, v.21, n.2, p.359-380, 2000.

Manica, I. Fruticultura tropical: Maracujá. São Paulo: Agronômica Ceres, 1981, 151p.

Medina, J.C.; Garcia, J.L.M.; Lara, L.C.C.; Tochini, R.P.; Hashizume, T.; Moretti, V.A.; Canto, W.L. Maracujá: da cultura ao processamento e comercialização. Campinas: Secretaria da Agricultura e Abastecimento/ITAL, 1980, 207p.

Menzel, C.M.; Haydon, G.F.; Simpson, D.R. Effect of nitrogen on growth and flowering of passionfruit (Passiflora edulis Sins f. edulis $x$ P. edulis f. flavicarpa) in sand culture. Journal of Horticultural Science, Ashford Kent, v.66, n.6, p.689-702, 1991.
Menzel, C.M; Simpson, D.R. Effect of continuous shading on growth, flowering and nutrient uptake of passion fruit. Scientia Horticulturae, Amsterdam, v.35, p.77-88, 1988.

Menzel, C.M; Simpson, D.R; Prince, G.H. Effect of foliar applied nitrogen during winter on growth, nitrogen content and production of passionfruit. Scientia Horticulturae, Amsterdam, v.28, p.339-346, 1986.

Phene, C.J.; Fouss, J.L.; Sanders, D.C. Water-nutrient-herbicide management of potatoes with trickle irrigation. American Potato Journal, Orono, v.56, p.51-59, 1979.

Ruggiero, C.; São José, A.R.; Volpe, C.A.; Oliveira, J.C. de; Durigan, J.F.; Baumgartner, J. G.; Silva, J.R. da; Nakamura, K.; Ferreira, M.E.; Kavati, R.; Pereira, V. de P. Maracujá para exportação: aspectos técnicos da produção. Brasília: EMBRAPA-SPI, 1996, 64p. Publicações Técnicas FRUPEX, 19

Santos, C.A.S. Distribuição espacial e absorção de água pelo sistema radicular da cultura da manga (Mangifera indica. $\mathrm{L}$ ) irrigada por microaspersão. Piracicaba: ESALQ, 1997. 151p. Dissertação Mestrado

Sousa, V.F. de. Freqüência de aplicação de N e K via água de irrigação por gotejamento no meloeiro (Cucumis melo L. cv. Eldorado 300) em solo de textura arenosa. Botucatu: UNESP, 1993. 131p. Dissertação Mestrado

Urashima, A.S. Aspectos fenológicos do maracujazeiro amarelo (Passiflora edulis Sims. var. flavicarpa Den.). Botucatu: FCA/ UNESP, 1985. 83p. Dissertação Mestrado 